\title{
Comparative validation of Monte Carlo codes for the conversion of a research reactor
}

\author{
V.P. Alferov ${ }^{\text {a }}$, A.I. Radaev ${ }^{\mathrm{a}}$, M.V. Shchurovskaya ${ }^{\mathrm{a}, *}$, G.V. Tikhomirov ${ }^{\mathrm{a}}$, N.A. Hanan ${ }^{\mathrm{b}}$, \\ F.A. van Heerden ${ }^{\mathrm{c}}$
}

${ }^{a}$ National Research Nuclear University MEPhI (Moscow Engineering Physics Institute),

31 Kashirskoe shosse, 115409 Moscow, Russia

${ }^{\mathrm{b}}$ GTRI Program, Nuclear Engineering Division, Argonne National Laboratory, 9700 Cass

Avenue, IL 60439 Argonne, USA

${ }^{\mathrm{c}}$ Research and Development, The South African Nuclear Energy Corporation (Necsa), Building 1900, P.O. Box 582, 0001 Pretoria, South Africa

\begin{abstract}
This paper presents the calculation results of the set of test problems for a research reactor with a tube-type low enriched uranium (LEU, $19.7 \mathrm{w} / \mathrm{o}, \mathrm{U}-9 \% \mathrm{Mo}$ ) fuel and oxide high enriched uranium (HEU, 90 w/o) fuel, a light water moderator, and a beryllium reflector. The static cases and the depletion problem were examined. Calculations were performed using continuous energy Monte Carlo codes: MCNP (+MCREB for burnup calculation), MCU-PTR, and SERPENT 2. The impact of the cross-section libraries used for a particular problem on the calculated results was investigated.
\end{abstract}

\section{Keywords:}

Research reactor, LEU fuel, Monte Carlo codes, validation of neutronics codes.

*Corresponding author. Tel.: +74993239242, Fax: +74993247026.

Email addresses: mvshchurovskaya@mephi.ru (Shchurovskaya, Maria V.), vpalferov@mephi.ru (Alferov, Vladimir P.), radaev_aleksandr@mail.ru (Radaev, Alexander I.), gvtikhomirov@mephi.ru (Tikhomirov, Georgy V.), nhanan@anl.gov (Hanan, Nelson A.), francois.vanheerden@necsa.co.za (van Heerden, Francois A.)

\section{Introduction}

Feasibility studies regarding the conversion of many research reactors to low enriched uranium (LEU) fuel are currently performed worldwide. In many cases, these studies stimulate the development and validation of research reactor core models and codes. Usually, the validation of neutronics calculation codes is based on the comparison either with criticality safety benchmark results (e.g., the International Criticality Safety Benchmark Evaluation Project (ICSBEP) (OECD/NEA, 2009)) or with the reactor plant operational data. However, there are still few evaluated benchmark results for heterogeneous thermal systems with LEU ( $20 \mathrm{w} / \mathrm{o})$ fuel, and the research reactor configuration is usually more heterogeneous compared to that found in critical assembly facilities [1]. No reactor experimental data exist for the new types of LEU fuel currently under development. Therefore, for the validation of the calculation models of the cores using the new types of fuel, the procedure of comparative validation of precision Monte Carlo codes was proposed. The comparison of the calculations conducted by Monte Carlo codes with different cross-section libraries is an important instrument for the validation of codes in the case when the experimental data are also available $[1,2]$.

The present work initially was performed for the conversion analysis of the IRT MEPhI research reactor at the National Research Nuclear University (NRNU) MEPhI. The IRT $\mathrm{MEPhI}$ is a 2.5-MW pool-type research reactor. Currently, IRT-3M high enriched uranium (HEU, 90 w/o) fuel assemblies are used. The feasibility studies were completed in November 
2011. For the feasibility studies of the IRT MEPhI reactor conversion, the tube-type fuel assembly IRT-3M with U9\%Mo-Al fuel (19.7 w/o) was chosen as the LEU fuel [3].

In the framework of the conversion feasibility studies, the detailed neutronics core analysis using the Monte Carlo codes MCNP [4] (using MCREB [5] for the burnup calculation) and MCU-PTR [6, 7] was performed. To validate the obtained results, a comparison was performed of the calculations using these codes on some test problems. The test problems were developed for the IRT-type reactor with U-Mo LEU fuel and oxide HEU. The real geometry of the fuel assembly was considered. The core configuration was simplified: the experimental channels, the end details of the fuel assemblies, the grid plate, among other features were not considered. The static cases and the depletion problem were examined.

The calculations of the proposed test problems can be used not only in the framework of the conversion analysis of a particular reactor but also for the validation of different codes. For example, the calculations of test problems were performed for the validation of SERPENT 2 $[8,9]$ code, which is used for the SAFARI reactor calculation.

\section{Models and codes}

\subsection{MCU-PTR}

The MCU-PTR code [6] was used for steady-state neutronics calculation and for the burnup calculation. MCU-PTR is the code for the calculations of pool- and tank-type research reactors in the framework of the MCU-5 package. The MCU-5 package [7] is intended for simulation of the transport of neutrons, photons, electrons, and positrons using analogous and weighted Monte Carlo methods. The MCU-5 package is used for the calculation of the different types of power and research reactors. The data bank of the MCU-5 package (MCUDB50) includes Russian libraries and the available foreign libraries. The MCUDB50 data bank contains the data for 375 isotopes.

According to [7], when simulating the collisions of neutrons with nuclei in different energy regions, it is possible to combine different data libraries. In the fast energy region, e.g., it is possible to use either the constants of the ACE/MCU library or the BNAB/MCU library. $\mathrm{ACE} / \mathrm{MCU}$ is the library of cross sections of neutron interaction with nuclei in the epithermal energy region in a pointwise representation obtained from the ENDF/B-VII.0 files and other sources. BNAB/MCU is an expanded and modified version of the BNAB-93 26-group system of constants. The energy boundaries of the regions for the use of ACE/MCU and $\mathrm{BNAB} / \mathrm{MCU}$ are defined by the code user.

In the thermalization region, it is possible to use a multigroup transport approximation or to perform a simulation using continuous-energy neutron interaction data.

The MCU-5 package has a burnup module that is intended for calculating the nuclide composition of the reactor materials in the process of reactor operation. The equations of isotopic composition kinetics are solved using an iterative (predictor corrector) method.

In the present work, two variants of MCU-PTR calculations were examined:

- using the $\mathrm{BNAB} / \mathrm{MCU}$ library for the energy region $\mathrm{E}>4.65 \mathrm{eV}$ (the ACE/MCU library is not used);

- using the ACE/MCU library for the energy region $100 \mathrm{keV}<\mathrm{E}<20 \mathrm{MeV}$ and the BNAB/MCU library for the energy region $2.15 \mathrm{eV}<\mathrm{E}<100 \mathrm{keV}$ ).

For the energy region $\mathrm{E}<2.15 \mathrm{eV}$ or $\mathrm{E}<4.65 \mathrm{eV}$ in both variants, the same continuousenergy neutron interaction data were used.

The MCU-PTR calculations were performed at NRNU MEPhI. 


\subsection{MCNP and MCREB}

The MCNP code [4] with the ENDF/B-VII.0-based cross-section libraries was used for the steady-state neutronics calculations of the test problems. The calculations with previous versions of ENDF/B were also performed.

The GTRI program at Argonne National Laboratory (ANL) developed a relatively easy method to perform Monte Carlo burnup analyses [10]. The Monte Carlo burnup analyses are performed using the MCREB code. This code uses the MCNP code for the calculation of $\mathrm{K}_{\mathrm{eff}}$, neutron fluxes, and cross-sections. These one-group neutron fluxes and cross sections (capture, fission, $n-2 n, n-\alpha$, and n-p) are then supplied to the REBUS [11] code for the power normalization and calculation of the burnup-buildup of the relevant isotopes. The REBUS code then supplies the "burned" compositions for the MCNP code for the next step in the analysis.

The MCNP calculations with the ENDF/B-VII.0-based cross-section libraries and the calculations using the MCREB code were performed at ANL.

The MCNP calculations with the ENDF/B-VI and ENDF/B-V-based cross-section libraries were performed at NRNU MEPhI.

\subsection{SERPENT 2}

The Monte Carlo reactor physics code SERPENT 2 [8,9] with the ENDF/B-VII-based crosssection libraries was used for the steady-state neutronics calculation and for the purpose of simulating depletion of the core. SERPENT 2 uses continuous energy ACE format data libraries. With the exception of the thermal cross sections for beryllium, all libraries used in this study were based on the ENDF/B-VII.0 evaluation. For the depletion studies, ENDF/BVII.0-based fission yield and decay libraries were also used. Depletion was performed with the built-in depletion module utilizing the predictor-corrector method.

The SERPENT 2 calculations were performed at Necsa.

\section{Test problem description}

The cross-sectional view of the IRT-3M fuel assembly (FA) with LEU fuel is shown in Fig. 1. The 6-tube FA consists of 6 co-axial fuel tubes with a control rod (CR) channel in the center. The dimensions of the 6-tube FA are presented in Table 1. The outer and inner dimensions of the fuel tube (S1 and S2, respectively) and the outer and inner radii of the rounded corners ( $\mathrm{R}$ and $\mathrm{r}$, respectively) are presented. The first tube is the outer tube.

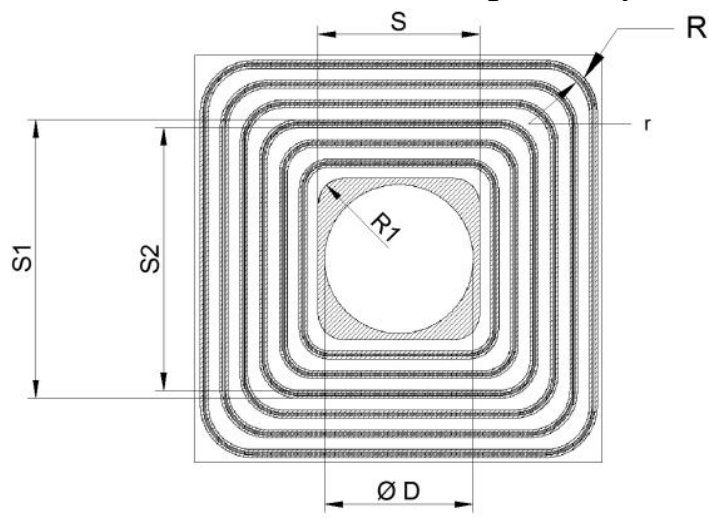

Table 1

FA dimensions, $\mathrm{cm}$

\begin{tabular}{ccccc}
\hline Tube \# & S1 & S2 & R & r \\
\hline 1 & 6.94 & 6.66 & 0.92 & 0.78 \\
2 & 6.25 & 5.97 & 0.84 & 0.7 \\
3 & 5.56 & 5.28 & 0.76 & 0.62 \\
4 & 4.87 & 4.59 & 0.68 & 0.54 \\
5 & 4.18 & 3.9 & 0.6 & 0.46 \\
6 & 3.49 & 3.21 & 0.52 & 0.38 \\
\hline
\end{tabular}

Fig. 1. FA geometry

The outer dimensions of the IRT-3M FA with HEU fuel are the same as the dimensions of the FA with LEU fuel, except for the radii of the rounded corners ( $\mathrm{R}=\mathrm{r}=0.4 \mathrm{~cm}$ for all tubes). 
Table 2 presents the data regarding the 6-tube FA IRT-3M with LEU and HEU fuel used in the study.

Table 2

LEU and HEU FA parameters

\begin{tabular}{lcc}
\hline Parameter & LEU & HEU \\
\hline U density, g/cc & 5.4 & 1.07 \\
${ }^{235}$ U mass in FA, g & 355.1 & 263.7 \\
Enrichment, \% & 19.7 & 90 \\
Fuel composition & (U-Mo)-Al & $\mathrm{UO}_{2}-\mathrm{Al}$ \\
Mo weight fraction in U-Mo & 0.09 & - \\
Meat thickness, cm & 0.05 & 0.04 \\
Clad thickness, cm & 0.045 & 0.05 \\
Clad material & $\mathrm{Al}$ & $\mathrm{Al}$ \\
Meat length, cm & 58 & 58 \\
Meat volume, cc & 333.8 & 274.69 \\
\hline
\end{tabular}

Table 3 presents the general description of the reactor design parameters for the test problems.

Table 3

Reactor design parameters

\begin{tabular}{lc}
\hline Parameter & Value \\
\hline Reactor type & Pool-type \\
Power, MW & 2.5 \\
FA number & $12-16$ \\
Lattice pitch, cm & 7.15 \\
Reflector & $\mathrm{Be}, \mathrm{Al}, \mathrm{H}_{2} \mathrm{O}$ \\
Moderator, coolant & $\mathrm{H}_{2} \mathrm{O}$ \\
Reflector block dimensions, cm & $6.9 \times 6.9 \times 58$ \\
Water temperature, ${ }^{\circ} \mathrm{C}$ & 20 \\
Fuel temperature, ${ }^{\circ} \mathrm{C}$ & 20 \\
Absorber outer radius, cm & 1.06 \\
Absorber length, cm & 58 \\
Absorber clad outer radius, cm & 1.15 \\
Absorber material & $\mathrm{B}_{4} \mathrm{C}$ \\
Absorber clad material & Steel \\
\hline
\end{tabular}

The core consists of 48 cells $(6 \times 8$ positions) for the FA and reflector blocks. There is water between FA (reflector blocks) and in the cells without FA or reflector blocks. The core height is $58 \mathrm{~cm}$. The water reflector thickness is $3 \times 7.15 \mathrm{~cm}$ in the X-Y direction and $29 \mathrm{~cm}$ in the axial direction. The vacuum boundary condition (BC) is used at the external border. One-half of the described system in the axial direction is considered for all of the test problems. Additionally, for the test depletion problem, one-half of the described system in the horizontal plane is considered. Reflection boundary conditions are used at the symmetry axes. The top and bottom reflectors are water. The control rod consists of an absorber rod in the cladding of stainless steel. The control rod is placed in the channel in the center of the FA. One-half of the core with 12 FA in the horizontal plane is presented in Fig. 2. 

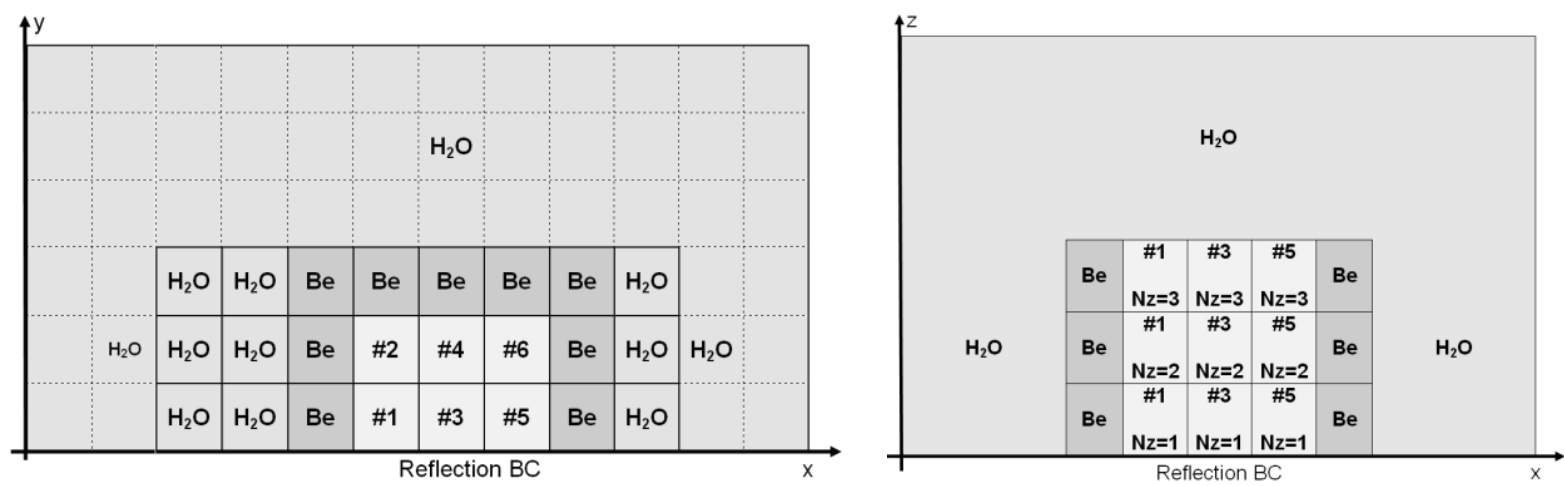

Fig. 2 Core diagram (\#1 to \#6 - FA numbers, $\mathrm{Nz}=1$ to 3 - number of axial layers)

\section{Results and discussion}

\subsection{Steady-state neutronics calculation}

The calculations were performed for six core configurations with different numbers of FAs and different reflectors. Fig. 3 presents the full core diagrams (without symmetry conditions).

\begin{tabular}{|c|c|c|c|c|c|c|c|}
\hline $\mathrm{H}_{2} \mathrm{O}$ & $\mathrm{H}_{2} \mathrm{O}$ & $\mathrm{Be}$ & $\mathrm{Be}$ & $\mathrm{Be}$ & $\mathrm{Be}$ & $\mathrm{Be}$ & $\mathrm{H}_{2} \mathrm{O}$ \\
\hline $\mathrm{H}_{2} \mathrm{O}$ & $\mathrm{H}_{2} \mathrm{O}$ & $\mathrm{Be}$ & $\mathrm{FA}$ & $\mathrm{FA}$ & $\mathrm{FA}$ & $\mathrm{Be}$ & $\mathrm{H}_{2} \mathrm{O}$ \\
\hline $\mathrm{H}_{2} \mathrm{O}$ & $\mathrm{H}_{2} \mathrm{O}$ & $\mathrm{Be}$ & $\mathrm{FA}$ & $\begin{array}{c}\mathrm{FA} \\
\text { (CR) }\end{array}$ & FA & $\mathrm{Be}$ & $\mathrm{H}_{2} \mathrm{O}$ \\
\hline $\mathrm{H}_{2} \mathrm{O}$ & $\mathrm{H}_{2} \mathrm{O}$ & $\mathrm{Be}$ & $\mathrm{FA}$ & $\begin{array}{c}\text { FA } \\
\text { (CR) }\end{array}$ & FA & Be & $\mathrm{H}_{2} \mathrm{O}$ \\
\hline $\mathrm{H}_{2} \mathrm{O}$ & $\mathrm{H}_{2} \mathrm{O}$ & $\mathrm{Be}$ & $\mathrm{FA}$ & FA & FA & $\mathrm{Be}$ & $\mathrm{H}_{2} \mathrm{O}$ \\
\hline $\mathrm{H}_{2} \mathrm{O}$ & $\mathrm{H}_{2} \mathrm{O}$ & $\mathrm{Be}$ & $\mathrm{Be}$ & $\mathrm{Be}$ & $\mathrm{Be}$ & $\mathrm{Be}$ & $\mathrm{H}_{2} \mathrm{O}$ \\
\hline
\end{tabular}

Core \#1

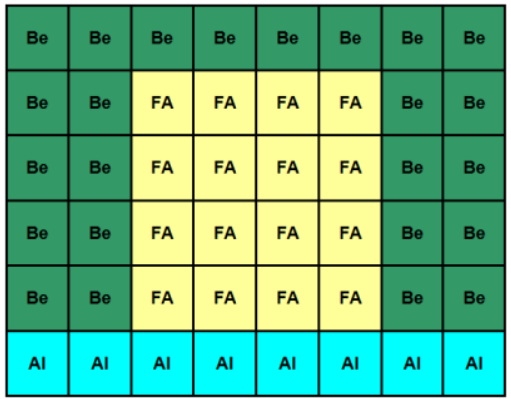

Core \#4

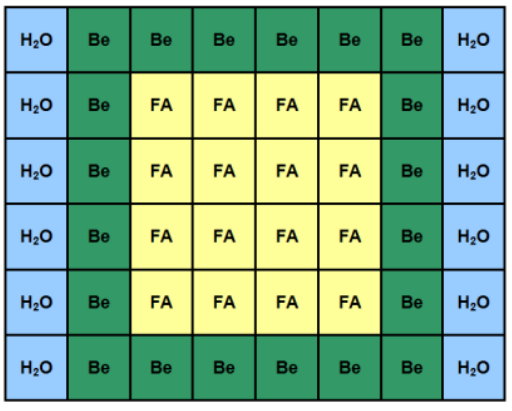

Core \#2

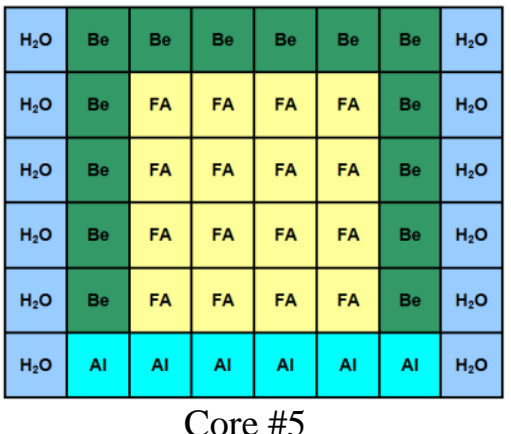

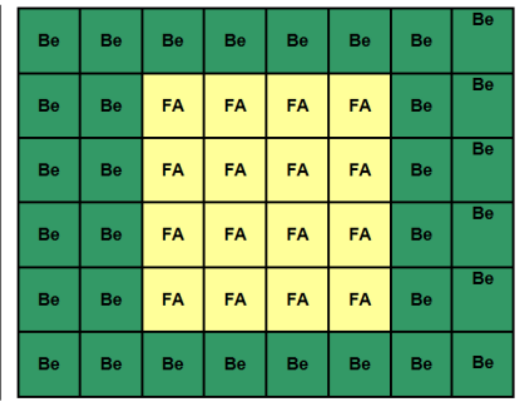

Core \#3

FA - 6-tube fuel assembly without CR; FA (CR) - 6-tube fuel assembly with CR; $\mathrm{Be}$ - beryllium block; Al- aluminum block; $\mathrm{H}_{2} \mathrm{O}$ - water.

\section{Fig. 3. Core configurations of the test problems}

The cores with HEU and LEU fuel were analyzed. Table 4 presents the case names, core numbers (in accordance with Fig. 3), fuel types and CR positions considered in this study. Calculation of the case $\mathrm{c} 2 \mathrm{r}$ was performed with two rods fully inserted. For the other cases, all of the rods are fully withdrawn. Xe-free cores with fresh FA were considered. Case d4Al represents a simplified version of the existing IRT MEPhI HEU core of 16 FA with beryllium and an aluminum reflector (without experimental channels and without burnup). After conversion, a core of 12 FA with a beryllium reflector is planned. The reduction of the FA number for the initial LEU is explained by the fact that the excess reactivity of the core with 16 fresh FA is too large. The case $\mathrm{c} 2$ represents the initial LEU core after conversion. Cases 
$\mathrm{c} 4 \mathrm{Al}, \mathrm{d} 2, \mathrm{~d} 3, \mathrm{~d} 3 \mathrm{al}$, and $\mathrm{d} 4$ were selected to investigate the impact of the reflector material, reflector configuration and FA number in the core on the discrepancy between the results calculated using different codes.

\section{Table 4}

Investigated cases

\begin{tabular}{ccccccccc}
\hline Case name & c2 & c2r & c4Al & d2 & d3 & d3Al & d4 & d4Al \\
\hline Core & $\# 1$ & $\# 1$ & $\# 4$ & $\# 1$ & $\# 2$ & $\# 5$ & $\# 3$ & $\# 4$ \\
Fuel & LEU & LEU & LEU & HEU & HEU & HEU & HEU & HEU \\
Rods & out & in & out & out & out & out & out & out \\
\hline
\end{tabular}

\subsubsection{Multiplication factor calculation}

For the selected core configurations, we compared the maximum deviation in the multiplication factor calculated using three codes (MCU-PTR, MCNP with ENDF/B-V and VI cross-section libraries, and SERPENT 2) from the reference variant and the spread of the discrepancy (the difference between the maximum and the minimum deviation from the reference variant for each code). The results calculated using the MCNP with ENDF/B-VII.0 cross-section libraries were selected as a reference variant. We consider the value $\leq 0.5 \% \Delta \mathrm{K} / \mathrm{K}$ as a desirable value for the maximum deviation and the value $\leq 0.3 \% \Delta \mathrm{K} / \mathrm{K}$ as a desirable value for the spread of the discrepancy.

The results of the $\mathrm{K}_{\text {eff }}$ calculation for 7 test problems (all rods withdrawn) using the MCNP with the ENDF/B-VII cross-section libraries and with the former ENDF/B-V and VI crosssection libraries as well as the results of the MCU-PTR calculations using the BNAB/MCU library for the energy region $\mathrm{E}>4.65 \mathrm{eV}$ are presented in Table 5. The difference in reactivity $\left.\left(\rho=100 \cdot\left(K_{\text {eff }}-1\right) / K_{\text {eff }}\right), \Delta \rho=\rho_{1}-\rho_{2}\right)$ between the MCNP/ENDF/B-VII results and the other results is also presented.

\section{Table 5}

Comparison of the MCNP (ENDF/B-VII, ENDF/B-VI and V) and MCU-PTR (BNAB/MCU library) calculation results (standard deviation $<0.0003$ )

\begin{tabular}{lccccc}
\hline Case & $\begin{array}{c}\text { MCNP/ } \\
\text { ENDF/B- } \\
\text { VII.0 }\end{array}$ & \multicolumn{2}{c}{ MCU-PTR/BNAB/MCU } & \multicolumn{2}{c}{ MCNP/ENDF/B-VI and V } \\
\cline { 3 - 6 } & & $\mathrm{K}_{\text {eff }}$ & $\begin{array}{c}\text { Difference } \Delta \rho, \\
\% \Delta \mathrm{K} / \mathrm{K}\end{array}$ & $\mathrm{K}_{\text {eff }}$ & $\begin{array}{c}\text { Difference } \Delta \rho, \\
\% \Delta \mathrm{K} / \mathrm{K}\end{array}$ \\
$\mathrm{c} 2$ & 1.1615 & 1.16028 & -0.09 & 1.1585 & -0.22 \\
$\mathrm{c} 4 \mathrm{Al}$ & 1.1904 & 1.1944 & 0.28 & 1.1852 & -0.37 \\
$\mathrm{~d} 2$ & 1.1933 & 1.1965 & $0.14)$ & & -0.02 \\
$\mathrm{~d} 3$ & 1.2513 & 1.2550 & 0.24 & 1.1930 & -0.06 \\
$\mathrm{~d} 3 \mathrm{Al}$ & 1.2061 & 1.2118 & 0.39 & 1.2503 & -0.06 \\
$\mathrm{~d} 4$ & 1.2731 & 1.2783 & 0.32 & 1.2053 & -0.04 \\
$\mathrm{~d} 4 \mathrm{Al}$ & 1.2248 & 1.2326 & 0.52 & 1.2223 & -0.16 \\
\hline $\mathrm{n}$ & & $(1.1924)^{\mathrm{b}}$ & 0.22 & \\
\hline
\end{tabular}

${ }^{\mathrm{a}}$ - for the case of MCNP/ENDF/B-VI and V cross-section data, 1001.62c, 8016.62c, 4009.62c, 92235.66c, 92238.66c, 13027.50c, $42000.50 \mathrm{c}$, lwtr.01t, and be.01t were used. ${ }^{\mathrm{b}}$ - Mo is in the form of a set of isotopes; in the other cases, Mo is Mo-nat.

As presented in Table 5, for the HEU cases using the ENDF/B-VI cross sections and the previous version of ENDF/B for beryllium, aluminum and water in the MCNP calculations 
results in the change in the $\mathrm{K}_{\text {eff }}$ values of up to $0.2 \% \Delta \mathrm{K} / \mathrm{K}$, in comparison with the calculations using ENDF/B-VII. For the LEU cases, this change is larger, which could be due to the Mo presence.

The discrepancy between the results from the MCNP/ENDF/B-VII and the results from the MCU-PTR with the BNAB/MCU library is larger for the core configurations with Al blocks; additionally, this discrepancy is different for the LEU and HEU cores. The value of this discrepancy for every considered case is not very large, but it is not a constant bias, and there is a spread in the discrepancy of approximately $0.6 \% \Delta \mathrm{K} / \mathrm{K}$ (the spread in the discrepancy was obtained as the difference between the maximum and the minimum deviation from the reference case). That is, if we consider the transition from the core $\mathrm{d} 4 \mathrm{Al}$ to the core $\mathrm{c} 2$, the discrepancy between MCNP/ENDF/B-VII and MCU-PTR/BNAB/MCU in the prediction of the excess reactivity change can be approximately $0.6 \% \Delta \mathrm{K} / \mathrm{K}$.

To extend the inter-code and inter-library comparison for the selected core configurations (c2, c4Al and d4Al), some additional investigations were performed. The case of the $\mathrm{c} 2$ core with two central rods fully inserted is also considered (case c2r).

The results of the $\mathrm{K}_{\mathrm{eff}}$ calculation for the 3 test problems (all rods withdrawn, except for the case c2r) using MCNP with several cross-section libraries, MCU-PTR and SERPENT 2 are presented in Table 6. The MCU-PTR calculations were performed using either the $\mathrm{BNAB} / \mathrm{MCU}$ library for the energy region $\mathrm{E}>4.65 \mathrm{eV}$ or using the ACE/MCU library for the energy region of $100 \mathrm{keV}<\mathrm{E}<20 \mathrm{MeV}$ and the BNAB/MCU library for the energy region of $2.15 \mathrm{eV}<\mathrm{E}<100 \mathrm{keV}$. For the inter-library comparison, we substituted a single ENDF/B-VII nuclide with the other library in the MCNP calculations and assessed the change in the $\mathrm{K}_{\mathrm{eff}}$ values. The MCNP/ENDF/B-VII result is a reference variant, as presented in Table 6.

Table 6

Comparison of MCNP (ENDF/B-VII and ENDF/B-VI and V), MCU-PTR (BNAB/MCU and ACE/MCU) and SERPENT 2 calculation results (standard deviation < 0.0003 )

\begin{tabular}{|c|c|c|c|c|c|}
\hline \multirow[t]{2}{*}{ Code } & \multirow[t]{2}{*}{$\begin{array}{l}\text { Libraries } \\
\text { (except for) }\end{array}$} & \multicolumn{4}{|c|}{$\begin{array}{c}\mathrm{K}_{\mathrm{eff}} \\
\text { (difference } \Delta \rho, \% \Delta \mathrm{K} / \mathrm{K} \text { ) }\end{array}$} \\
\hline & & $\mathrm{c} 4 \mathrm{Al}$ & $\mathrm{d} 4 \mathrm{Al}$ & $\mathrm{c} 2$ & $\mathrm{c} 2 \mathrm{r}$ \\
\hline MCNP & ENDF/B-VII.0 & $\begin{array}{c}1.1904 \\
(-)\end{array}$ & $\begin{array}{c}1.2248 \\
(-)\end{array}$ & $\begin{array}{c}1.1615 \\
(-)\end{array}$ & $\begin{array}{c}1.0836 \\
(-)\end{array}$ \\
\hline MCNP & $\begin{array}{l}\text { ENDF/B-VII.0, } \\
(42000.66 \mathrm{c})\end{array}$ & $\begin{array}{l}1.1882 \\
(-0.16)\end{array}$ & N/A & $\begin{array}{l}1.1599 \\
(-0.12)\end{array}$ & $\begin{array}{l}1.0821 \\
(-0.13)\end{array}$ \\
\hline MCNP & $\begin{array}{l}\text { ENDF/B-VII.0, } \\
\text { (Be-ENDF/B-VI) }\end{array}$ & $\begin{array}{l}1.1916 \\
(0.08)\end{array}$ & $\begin{array}{l}1.2259 \\
(0.07)\end{array}$ & $\begin{array}{l}1.1627 \\
(0.09)\end{array}$ & $\begin{array}{l}1.0857 \\
(0.18)\end{array}$ \\
\hline MCNP & ENDF/B-VI ${ }^{a}$ & $\begin{array}{l}1.1872 \\
(-0.23)\end{array}$ & $\begin{array}{l}1.2250 \\
(0.01)\end{array}$ & $\begin{array}{l}1.1590 \\
(-0.19)\end{array}$ & $\begin{array}{l}1.0822 \\
(-0.12)\end{array}$ \\
\hline MCU-PTR & ACE/MCU & $\begin{array}{l}1.1879 \\
(-0.18)\end{array}$ & $\begin{array}{l}1.2253 \\
(0.03)\end{array}$ & $\begin{array}{l}1.1587 \\
(-0.21)\end{array}$ & $\begin{array}{l}1.0796 \\
(-0.34)\end{array}$ \\
\hline MCU-PTR & $\mathrm{BNAB} / \mathrm{MCU}$ & $\begin{array}{l}1.1944 \\
(0.28)\end{array}$ & $\begin{array}{l}1.2326 \\
(0.52)\end{array}$ & $\begin{array}{l}1.1603 \\
(-0.09)\end{array}$ & $\begin{array}{l}1.0848 \\
(0.10)\end{array}$ \\
\hline SERPENT 2 & $\begin{array}{l}\text { ENDF/B-VII.0, } \\
\text { (be.60t) }\end{array}$ & $\begin{array}{l}1.1912 \\
(0.05)\end{array}$ & - & - & $\begin{array}{l}1.0857 \\
(0.18)\end{array}$ \\
\hline
\end{tabular}

${ }^{\mathrm{a}}$ - for the case of MCNP/ENDF/B-VI cross-section data, 001.62c, 4009.62c, 8016.62c, 13027.92c, 42000.66c, $92235.66 \mathrm{c}, 92238.66 \mathrm{c}, 5010.66 \mathrm{c}, 5011.66 \mathrm{c}, 26000.50 \mathrm{c}$, be.60t, and lwtr.60t were used. 
From Table 6, the results from MCU-PTR with the ACE/MCU library give better agreement with the MCNP/ENDF/B-VII calculations than the results from MCU-PTR with the $\mathrm{BNAB} / \mathrm{MCU}$ library. The spread in the discrepancy is $0.37 \% \Delta \mathrm{K} / \mathrm{K}$ for all of the considered cases.

The values of $\mathrm{CR}$ worth, which is defined as the difference between the reactivity of cases c2 and $\mathrm{c} 2 \mathrm{r}$, were found to be $6.19 \% \Delta \mathrm{K} / \mathrm{K}$ (MCNP/ENDF/B-VII), 6.32\% $\Delta \mathrm{K} / \mathrm{K}$ (MCU$\mathrm{PTR} / \mathrm{ACE} / \mathrm{MCU}$ ) and $6.0 \% \Delta \mathrm{K} / \mathrm{K}$ (MCU-PTR/ BNAB/MCU). The discrepancy with $\mathrm{MCNP} / \mathrm{ENDF} / \mathrm{B}-\mathrm{VII}$ in the $\mathrm{CR}$ worth is $+2.2 \%$ (relative) and $-3.1 \%$ for the results from MCU-PTR with ACE/MCU and the results from MCU-PTR with BNAB/MCU, respectively. Both discrepancies are satisfactory.

When identical cross-section libraries are used in the SERPENT 2 and MCNP calculations, the codes provide the same value of $\mathrm{K}_{\mathrm{eff}}$ (the calculation of the $\mathrm{c} 2 \mathrm{r}$ and $\mathrm{c} 4 \mathrm{al}$ cases used the SERPENT 2 and the MCNP with ENDF/B-VII cross sections for all isotopes, except for beryllium).

The cross sections for Be-9 and Mo were found to primarily contribute to the difference in the $\mathrm{K}_{\mathrm{eff}}$ between the results from MCNP/ENDF/B-VII and the results from the previous version of $\mathrm{ENDF} / \mathrm{B}$.

\subsubsection{Integral balance and the rates of basic nuclear reactions in the reactor volume}

Table 7 presents the results of the comparison of the integral reaction rates for the different isotopes calculated with MCNP/ENDF/B-VI ( $\mathrm{K}_{\mathrm{eff}}=1.1872$ for $\mathrm{c} 4 \mathrm{Al}$ and $\mathrm{K}_{\mathrm{eff}}=1.2250$ for $\mathrm{d} 4 \mathrm{Al})$, MCU-PTR/BNAB/MCU $\left(\mathrm{K}_{\mathrm{eff}}=1.1944\right.$ for $\mathrm{c} 4 \mathrm{Al}$ and $\mathrm{K}_{\mathrm{eff}}=1.2326$ for $\left.\mathrm{d} 4 \mathrm{Al}\right)$ and MCU-PTR/ACE/MCU ( $\mathrm{K}_{\text {eff }}=1.1879$ for $\mathrm{c} 4 \mathrm{Al}$ and $\mathrm{K}_{\mathrm{eff}}=1.2253$ for $\left.\mathrm{d} 4 \mathrm{Al}\right)$. Both the MCNP and MCU-PTR tallies are for one fission neutron generation. The standard deviation for the presented integral reaction rates is in the range of $0.02 \%$ to $0.07 \%$. 
Table 7

Integral balance and rates of the basic nuclear reactions in the reactor volume

\begin{tabular}{|c|c|c|c|c|c|c|}
\hline \multirow{2}{*}{ Functional $^{\mathrm{a}}$} & \multirow{2}{*}{ Isotope } & \multirow{2}{*}{ MCNP } & \multicolumn{2}{|c|}{ MCU-PTR } & \multicolumn{2}{|c|}{ (MCU-MCNP)/MCNP, \% } \\
\hline & & & $\mathrm{BNAB} / \mathrm{MCU}$ & $\mathrm{ACE} / \mathrm{MCU}$ & BNAB/MCU & ACE/MCU \\
\hline \multicolumn{7}{|c|}{ HEU fuel (d4Al) } \\
\hline \multirow[t]{8}{*}{ A } & $\mathrm{U} 235$ & 0.602 & 0.611 & 0.607 & 1.5 & 0.8 \\
\hline & $\mathrm{U} 238$ & $3.980 \mathrm{E}-03$ & 4.071E-03 & $4.043 \mathrm{E}-03$ & 2.3 & 1.6 \\
\hline & $\mathrm{U} 234$ & $2.020 \mathrm{E}-03$ & $1.956 \mathrm{E}-03$ & $1.944 \mathrm{E}-03$ & -3.2 & -3.8 \\
\hline & AL & $4.326 \mathrm{E}-02$ & 4.362E-02 & 4.364E-02 & 0.8 & 0.9 \\
\hline & $\mathrm{O}$ & $2.513 \mathrm{E}-03$ & $1.804 \mathrm{E}-03$ & $1.933 \mathrm{E}-03$ & -28.2 & -23.1 \\
\hline & BE9 & $1.912 \mathrm{E}-02$ & $1.971 \mathrm{E}-02$ & $1.931 \mathrm{E}-02$ & 3.1 & 1.0 \\
\hline & $\mathrm{H}$ & $3.448 \mathrm{E}-01$ & $3.439 \mathrm{E}-01$ & $3.472 \mathrm{E}-01$ & -0.3 & 0.7 \\
\hline & total & 1.018 & 1.026 & 1.025 & 0.8 & 0.7 \\
\hline$(\mathrm{n}, 2 \mathrm{n})$ & BE9 & $2.212 \mathrm{E}-02$ & $2.324 \mathrm{E}-02$ & $2.271 \mathrm{E}-02$ & 5.1 & 2.7 \\
\hline $\mathrm{L}$ & & $4.542 \mathrm{E}-03$ & $4.318 \mathrm{E}-03$ & 4.477E-03 & -4.9 & -1.4 \\
\hline \multirow[t]{4}{*}{$\mathrm{F}$} & $\mathrm{U} 235$ & 0.5022 & 0.5104 & 0.5074 & 1.6 & 1.0 \\
\hline & $\mathrm{U} 238$ & $6.216 \mathrm{E}-05$ & $6.342 \mathrm{E}-05$ & $6.264 \mathrm{E}-05$ & 2.0 & 0.8 \\
\hline & $\mathrm{U} 234$ & 3.672E-05 & $3.844 \mathrm{E}-05$ & 3.727E-05 & 4.7 & 1.5 \\
\hline & Total & 0.502 & 0.510 & 0.507 & 1.6 & 1.0 \\
\hline \multicolumn{7}{|c|}{ LEU fuel (c4AI) } \\
\hline \multirow[t]{4}{*}{ A } & $\mathrm{U} 235$ & 0.582 & 0.590 & 0.587 & 1.4 & 0.9 \\
\hline & $\mathrm{U} 238$ & $5.821 \mathrm{E}-02$ & $5.97 \mathrm{E}-02$ & 5.94E-02 & 2.6 & 2.0 \\
\hline & MO & $8.446 \mathrm{E}-03$ & $7.97 \mathrm{E}-03$ & $7.93 \mathrm{E}-03$ & -5.6 & -6.1 \\
\hline & BE9 & 1.79E-02 & $1.85 \mathrm{E}-02$ & $1.81 \mathrm{E}-02$ & 3.4 & 1.1 \\
\hline \multirow[t]{3}{*}{$\mathrm{F}$} & $\mathrm{U} 235$ & 0.4832 & 0.4907 & 0.488 & 1.6 & 1.0 \\
\hline & $\mathrm{U} 238$ & $3.251 \mathrm{E}-03$ & $3.313 \mathrm{E}-03$ & $3.264 \mathrm{E}-03$ & 1.9 & 0.4 \\
\hline & total & 0.486 & 0.494 & 4.91E-01 & 1.6 & 1.0 \\
\hline
\end{tabular}

${ }^{\mathrm{a}} \mathrm{A}$ - rate of absorption reaction, $(\mathrm{n}, 2 \mathrm{n})$ - rate of $(\mathrm{n}, 2 \mathrm{n})$ reaction, $\mathrm{L}$ - neutron leakage, and $\mathrm{F}$ - rate of fission reaction.

The difference in the absorption and fission reaction rates of ${ }^{235} \mathrm{U}$ is primarily responsible for the discrepancy between the MCU-PTR and MCNP results. From Table 7, the MCU$\mathrm{PTR} / \mathrm{ACE} / \mathrm{MCU}$ reaction rate calculation results are observed to provide better agreement with the MCNP/ENDF/B-VI calculations than the MCU-PTR/BNAB/MCU reaction rate calculation results.

\subsection{Burnup calculation}

This test problem illustrates the change in the excess reactivity of the reactor core of 12 LEU FA during the first burnup cycle. At the first time step, the Xe-free core with fresh FA is considered. For the fresh core, the compositions of all of the fuel zones are the same. Two CRs are fully inserted: in FA\#3 and in the FA symmetrical to it (the FA numeration is shown in Fig. 2). The reactor operation at full power is calculated. The integral energy generation of the core during the first cycle is $20000 \mathrm{MWh}$ (333.3 full power days). The reactor power is 2.5 MW. One-quarter of the real core with symmetry boundary conditions was calculated; therefore, the power of $625 \mathrm{~kW}$ was produced in calculation. It is assumed that in the horizontal plane, all fuel tubes of one FA have the same burnup (i.e., they burn as one material). There are 3 burnup layers in the axial direction. The numeration of the axial segments is presented in Fig. 2 (Nz). The CR position does not change during the burnup process. ${ }^{10} \mathrm{~B}$ burnup in the control rods and beryllium poisoning are not considered. 
Table 8 and Fig. 4 present the results of the multiplication factor calculation using three codes: MCREB code (the linkage between the REBUS-PC and MCNP codes), MCU-PTR and SERPENT 2. The difference (in $\% \triangle \mathrm{K} / \mathrm{K}$ ) between the MCU-PTR and MCREB results and between the SERPENT 2 and MCREB results is also shown in Fig. 4.

\section{Table 8}

Neutron multiplication factor vs. burnup during the first cycle

\begin{tabular}{|c|c|c|c|c|c|c|}
\hline \multirow{2}{*}{ Full power days } & \multicolumn{2}{|c|}{ MCREB } & \multicolumn{2}{|c|}{ MCU-PTR } & \multicolumn{2}{|c|}{ SERPENT 2} \\
\hline & $\mathrm{K}_{\mathrm{eff}}^{\mathrm{b}}$ & $\rho, \% \Delta \mathrm{K} / \mathrm{K}$ & $\mathrm{K}_{\mathrm{eff}}^{\mathrm{c}}$ & $\rho, \% \Delta K / K$ & $\mathrm{~K}_{\mathrm{efff}}{ }^{\mathrm{d}}$ & $\rho, \% \Delta K / K$ \\
\hline $0^{\mathrm{a}}$ & 1.08209 & 7.59 & 1.08479 & 7.82 & 1.0857 & 7.89 \\
\hline 1 & 1.05429 & 5.15 & 1.0568 & 5.37 & 1.05804 & 5.49 \\
\hline 2 & 1.04969 & 4.73 & 1.05209 & 4.95 & 1.05313 & 5.04 \\
\hline 3 & 1.04854 & 4.63 & 1.05114 & 4.87 & 1.05226 & 4.97 \\
\hline 33.3 & 1.03523 & 3.40 & 1.03776 & 3.64 & 1.03883 & 3.74 \\
\hline 99.99 & 1.01898 & 1.86 & 1.0219 & 2.14 & & \\
\hline 166.7 & 1.00347 & 0.35 & 1.00628 & 0.62 & 1.00751 & 0.75 \\
\hline 250 & 0.98317 & -1.71 & 0.98615 & -1.40 & & \\
\hline 333.3 & 0.96148 & -4.01 & 0.96483 & -3.64 & 0.96572 & -3.55 \\
\hline $333.3^{\mathrm{a}}$ & 0.99062 & -0.95 & 0.99281 & -0.72 & & \\
\hline
\end{tabular}

The depletion step for time > 33 days was as follows: MCREB - 16.66 days, MCU-PTR - as presented in Table 8 (66.7 days and 83.3 days), and SERPENT 2 - as presented in Table 8 (133.4 days and 166.6 days), but the built-in predictor corrector method was used to reduce the effect of large time steps.

The MCREB calculation accounted for 45 actinides and fission products as well as a lumped fission product. The MCU-PTR calculation accounted for 47 actinides and fission products, and the other isotopes were calculated with lumped fission product cross sections.

SERPENT 2 tracked a total of 284 isotopes, which included the fission products, actinides, and activation of the non-fuel materials in the fuel assembly. No lumping was performed during the simulation.

There is a bias of $\sim 0.3 \% \Delta \mathrm{K} / \mathrm{K}$ among the MCU-PTR, SERPENT 2 and MCREB results at the beginning of the cycle. As demonstrated above, the bias is related to the use of the different cross-section libraries. Up to the end of the cycle, the bias increases to $0.1 \%$. 


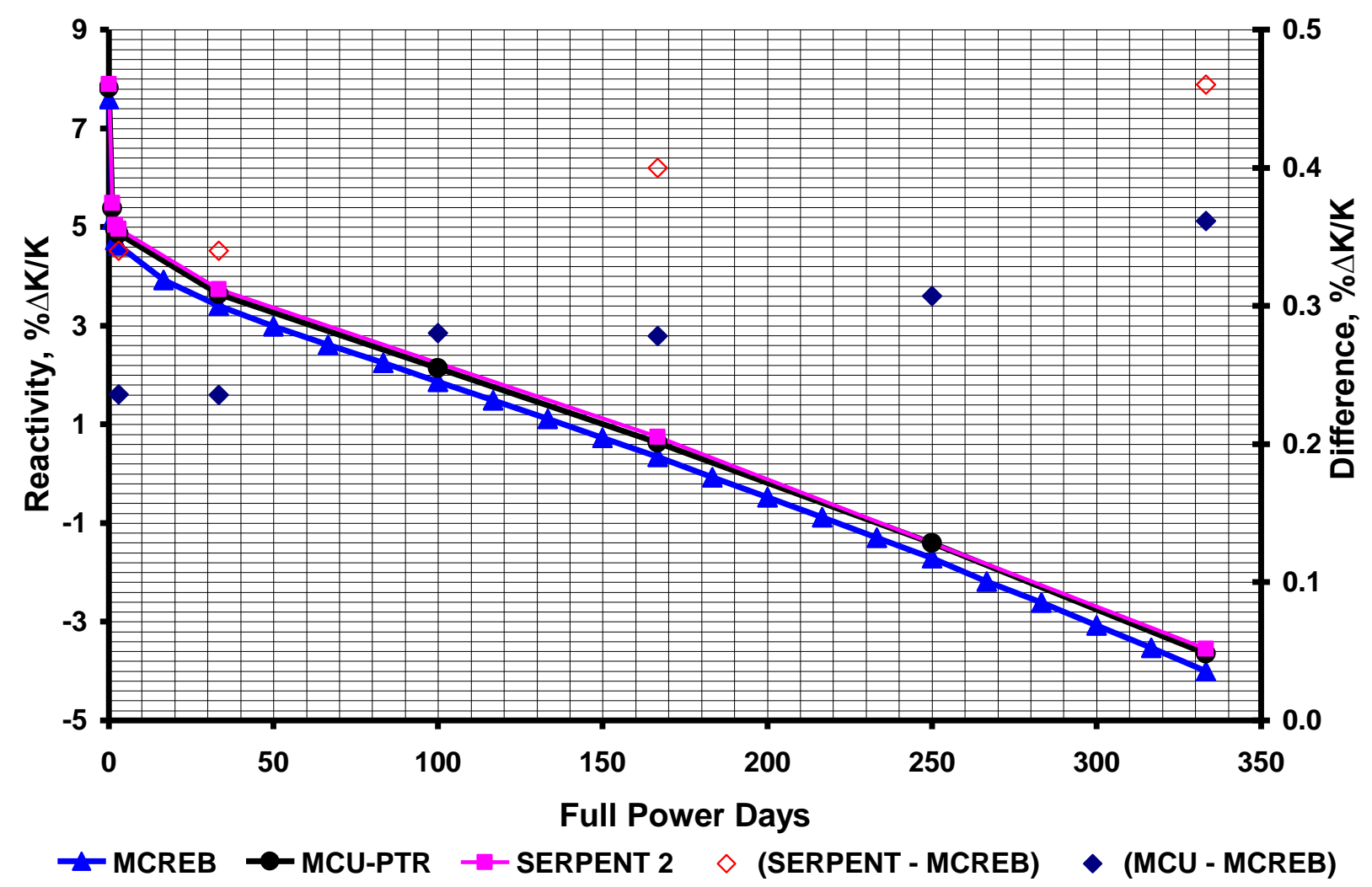

Fig. 4. Reactivity vs. time calculated using MCREB, MCU-PTR and SERPENT 2

Table 9 compares the end-of-cycle atomic densities of ${ }^{235} \mathrm{U},{ }^{236} \mathrm{U},{ }^{239} \mathrm{Pu}$, and ${ }^{240} \mathrm{Pu}$. The standard deviation for the presented number densities is as follows: ${ }^{235} \mathrm{U}-<0.1 \%,{ }^{236} \mathrm{U}-$ $<0.2 \%,{ }^{239} \mathrm{Pu}-<0.4 \%$, and ${ }^{240} \mathrm{Pu}-<0.8 \%$.

Table 8

Atomic densities of ${ }^{235} \mathrm{U},{ }^{236} \mathrm{U},{ }^{239} \mathrm{Pu}$, and ${ }^{240} \mathrm{Pu}$ at the end of the cycle

\begin{tabular}{|c|c|c|c|c|c|c|}
\hline \multirow{3}{*}{ \#FA } & \multirow{3}{*}{$\mathrm{Nz}$} & \multicolumn{3}{|c|}{ Atom densities, $1 /($ barn $\mathrm{cm})$} & \multicolumn{2}{|c|}{ Relation } \\
\hline & & \multicolumn{3}{|c|}{ Code } & \multirow{2}{*}{$\begin{array}{c}\text { MCU/ } \\
\text { MCREB }\end{array}$} & \multirow{2}{*}{$\begin{array}{l}\text { SERPENT/ } \\
\text { MCREB }\end{array}$} \\
\hline & & MCREB & MCU-PTR & SERPENT & & \\
\hline \multirow{3}{*}{1} & & & ${ }^{235} \mathbf{U}$ & & & \\
\hline & 1 & $1.887 \mathrm{E}-03$ & $1.887 \mathrm{E}-03$ & $1.904 \mathrm{E}-03$ & 1.000 & 1.009 \\
\hline & 2 & 2.009E-03 & $2.015 \mathrm{E}-03$ & $2.023 \mathrm{E}-03$ & 1.003 & 1.007 \\
\hline \multirow{3}{*}{2} & 3 & $2.208 \mathrm{E}-03$ & $2.221 \mathrm{E}-03$ & $2.212 \mathrm{E}-03$ & 1.006 & 1.002 \\
\hline & 1 & $1.878 \mathrm{E}-03$ & $1.883 \mathrm{E}-03$ & $1.891 \mathrm{E}-03$ & 1.003 & 1.007 \\
\hline & 2 & $2.002 \mathrm{E}-03$ & $2.012 \mathrm{E}-03$ & $2.013 \mathrm{E}-03$ & 1.005 & 1.005 \\
\hline \multirow{3}{*}{3} & 3 & $2.210 \mathrm{E}-03$ & $2.226 \mathrm{E}-03$ & $2.211 \mathrm{E}-03$ & 1.007 & 1.001 \\
\hline & 1 & $2.137 \mathrm{E}-03$ & $2.138 \mathrm{E}-03$ & $2.148 \mathrm{E}-03$ & 1.001 & 1.005 \\
\hline & 2 & $2.225 \mathrm{E}-03$ & $2.229 \mathrm{E}-03$ & $2.234 \mathrm{E}-03$ & 1.002 & 1.004 \\
\hline \multirow{4}{*}{4} & 3 & 2.357E-03 & $2.364 \mathrm{E}-03$ & 2.359E-03 & 1.003 & 1.001 \\
\hline & 1 & $1.916 \mathrm{E}-03$ & $1.917 \mathrm{E}-03$ & $1.928 \mathrm{E}-03$ & 1.000 & 1.006 \\
\hline & 2 & $2.036 \mathrm{E}-03$ & $2.041 \mathrm{E}-03$ & $2.044 \mathrm{E}-03$ & 1.003 & 1.004 \\
\hline & 3 & $2.230 \mathrm{E}-03$ & $2.241 \mathrm{E}-03$ & $2.230 \mathrm{E}-03$ & 1.005 & 1.000 \\
\hline
\end{tabular}


Continuation of Table 8

\begin{tabular}{|c|c|c|c|c|c|c|}
\hline \multirow{3}{*}{ \#FA } & \multirow{3}{*}{$\mathrm{Nz}$} & \multicolumn{3}{|c|}{ Atom densities, $1 /($ barn $\mathrm{cm})$} & \multicolumn{2}{|c|}{ Relation } \\
\hline & & & Code & & \multirow{2}{*}{$\begin{array}{c}\text { MCU/ } \\
\text { MCREB }\end{array}$} & \multirow{2}{*}{$\begin{array}{c}\text { SERPENT/ } \\
\text { MCREB }\end{array}$} \\
\hline & & MCREB & MCU-PTR & SERPENT & & \\
\hline & & & ${ }^{236} \mathbf{U}$ & & & \\
\hline \multirow[t]{3}{*}{1} & 1 & $1.404 \mathrm{E}-04$ & $1.391 \mathrm{E}-04$ & $1.375 \mathrm{E}-04$ & 0.991 & 0.980 \\
\hline & 2 & $1.204 \mathrm{E}-04$ & $1.185 \mathrm{E}-04$ & $1.181 \mathrm{E}-04$ & 0.984 & 0.981 \\
\hline & 3 & 8.603E-05 & $8.341 \mathrm{E}-05$ & $8.527 \mathrm{E}-05$ & 0.970 & 0.991 \\
\hline \multirow[t]{3}{*}{2} & 1 & $1.397 \mathrm{E}-04$ & $1.381 \mathrm{E}-04$ & $1.374 \mathrm{E}-04$ & 0.988 & 0.983 \\
\hline & 2 & $1.197 \mathrm{E}-04$ & $1.174 \mathrm{E}-04$ & $1.179 \mathrm{E}-04$ & 0.981 & 0.985 \\
\hline & 3 & $8.460 \mathrm{E}-05$ & $8.157 \mathrm{E}-05$ & $8.422 \mathrm{E}-05$ & 0.964 & 0.996 \\
\hline \multirow[t]{3}{*}{3} & 1 & $1.047 \mathrm{E}-04$ & $1.031 \mathrm{E}-04$ & $1.027 \mathrm{E}-04$ & 0.984 & 0.981 \\
\hline & 2 & $8.935 \mathrm{E}-05$ & $8.748 \mathrm{E}-05$ & $8.783 \mathrm{E}-05$ & 0.979 & 0.983 \\
\hline & 3 & $6.459 \mathrm{E}-05$ & $6.252 \mathrm{E}-05$ & $6.415 \mathrm{E}-05$ & 0.968 & 0.993 \\
\hline \multirow[t]{3}{*}{4} & 1 & $1.355 \mathrm{E}-04$ & $1.343 \mathrm{E}-04$ & $1.335 \mathrm{E}-04$ & 0.991 & 0.985 \\
\hline & 2 & $1.161 \mathrm{E}-04$ & $1.143 \mathrm{E}-04$ & $1.145 \mathrm{E}-04$ & 0.985 & 0.986 \\
\hline & 3 & $8.259 \mathrm{E}-05$ & $\begin{array}{l}{ }^{8.008 E-05} \\
{ }^{{ }^{239}} \mathbf{P u}\end{array}$ & $8.239 \mathrm{E}-05$ & 0.970 & 0.998 \\
\hline \multirow[t]{3}{*}{1} & 1 & $6.225 \mathrm{E}-05$ & $6.376 \mathrm{E}-05$ & $6.047 \mathrm{E}-05$ & 1.024 & 0.971 \\
\hline & 2 & $5.577 \mathrm{E}-05$ & $5.670 \mathrm{E}-05$ & $5.431 \mathrm{E}-05$ & 1.017 & 0.974 \\
\hline & 3 & $3.941 \mathrm{E}-05$ & $3.941 \mathrm{E}-05$ & $3.845 \mathrm{E}-05$ & 1.000 & 0.976 \\
\hline \multirow[t]{3}{*}{2} & 1 & $5.783 \mathrm{E}-05$ & $5.952 \mathrm{E}-05$ & $5.633 \mathrm{E}-05$ & 1.029 & 0.974 \\
\hline & 2 & $5.170 \mathrm{E}-05$ & $5.285 \mathrm{E}-05$ & $5.045 \mathrm{E}-05$ & 1.022 & 0.976 \\
\hline & 3 & $3.616 \mathrm{E}-05$ & $3.631 \mathrm{E}-05$ & $3.543 \mathrm{E}-05$ & 1.004 & 0.980 \\
\hline \multirow[t]{3}{*}{3} & 1 & $6.155 \mathrm{E}-05$ & $6.206 \mathrm{E}-05$ & $5.994 \mathrm{E}-05$ & 1.008 & 0.974 \\
\hline & 2 & $5.417 \mathrm{E}-05$ & $5.434 \mathrm{E}-05$ & $5.279 \mathrm{E}-05$ & 1.003 & 0.975 \\
\hline & 3 & $3.751 \mathrm{E}-05$ & $3.720 \mathrm{E}-05$ & $3.672 \mathrm{E}-05$ & 0.992 & 0.979 \\
\hline \multirow[t]{3}{*}{4} & 1 & $6.072 \mathrm{E}-05$ & $6.216 \mathrm{E}-05$ & $5.918 \mathrm{E}-05$ & 1.024 & 0.975 \\
\hline & 2 & $5.428 \mathrm{E}-05$ & $5.515 \mathrm{E}-05$ & $5.294 \mathrm{E}-05$ & 1.016 & 0.975 \\
\hline & 3 & 3.809E-05 & $\begin{array}{l}3.812 \mathrm{E}-05 \\
{ }^{240} \mathbf{P u}\end{array}$ & $3.750 \mathrm{E}-05$ & 1.001 & 0.985 \\
\hline \multirow[t]{3}{*}{1} & 1 & 7.497E-06 & $7.788 \mathrm{E}-06$ & 7.454E-06 & 1.039 & 0.994 \\
\hline & 2 & $5.750 \mathrm{E}-06$ & $5.896 \mathrm{E}-06$ & $5.747 \mathrm{E}-06$ & 1.025 & 0.999 \\
\hline & 3 & $2.883 \mathrm{E}-06$ & $2.864 \mathrm{E}-06$ & $2.917 \mathrm{E}-06$ & 0.993 & 1.012 \\
\hline \multirow[t]{3}{*}{2} & 1 & $6.962 \mathrm{E}-06$ & $7.216 \mathrm{E}-06$ & $6.949 \mathrm{E}-06$ & 1.037 & 0.998 \\
\hline & 2 & $5.304 \mathrm{E}-06$ & $5.431 \mathrm{E}-06$ & $5.317 \mathrm{E}-06$ & 1.024 & 1.002 \\
\hline & 3 & $2.586 \mathrm{E}-06$ & $2.557 \mathrm{E}-06$ & $2.644 \mathrm{E}-06$ & 0.989 & 1.023 \\
\hline \multirow[t]{3}{*}{3} & 1 & $5.472 \mathrm{E}-06$ & $5.610 \mathrm{E}-06$ & $5.417 \mathrm{E}-06$ & 1.025 & 0.990 \\
\hline & 2 & 4.139E-06 & 4.199E-06 & 4.113E-06 & 1.015 & 0.994 \\
\hline & 3 & $2.084 \mathrm{E}-06$ & $2.060 \mathrm{E}-06$ & $2.105 \mathrm{E}-06$ & 0.988 & 1.010 \\
\hline \multirow[t]{3}{*}{4} & 1 & 7.062E-06 & 7.332E-06 & 7.073E-06 & 1.038 & 1.002 \\
\hline & 2 & $5.400 \mathrm{E}-06$ & $5.539 \mathrm{E}-06$ & $5.424 \mathrm{E}-06$ & 1.026 & 1.004 \\
\hline & 3 & $2.680 \mathrm{E}-06$ & $2.662 \mathrm{E}-06$ & $2.752 \mathrm{E}-06$ & 0.993 & 1.027 \\
\hline
\end{tabular}


The maximum difference in the atomic densities is: ${ }^{235} \mathrm{U}-0.9 \%,{ }^{236} \mathrm{U}-2 \%,{ }^{239} \mathrm{Pu}-3 \%$, and ${ }^{240} \mathrm{Pu}-4 \%$.

The presented results demonstrate a good agreement between the calculations performed using the chosen codes.

\section{Summary and conclusions}

The calculation of the set of test problems for the IRT-type research reactor with a tube-type LEU (U-Mo) and HEU fuel, a light water moderator and a beryllium reflector was performed using the different three-dimensional continuous-energy Monte Carlo codes (MCNP, MCUPTR and SERPENT 2). Effective multiplication factors in the core for several loading patterns were used in the validation process of the physical model of the core.

The difference in the multiplication factor between the results of the MCNP with ENDF/BVII and the results of the MCNP with ENDF/B-VI is approximately $0.1 \% \Delta \mathrm{K} / \mathrm{K}$ for the core with HEU fuel; for the LEU case, this difference is approximately $0.2 \% \Delta \mathrm{K} / \mathrm{K}$.

The discrepancy between the results of MCNP/ENDF/B-VII and the results of MCU-PTR with the BNAB/MCU library is from $-0.1 \% \Delta \mathrm{K} / \mathrm{K}$ to $0.5 \% \Delta \mathrm{K} / \mathrm{K}$ for HEU and LEU fuel. The discrepancy between the results of $\mathrm{MCNP} / \mathrm{ENDF} / \mathrm{B}-\mathrm{VII}$ and the results of MCU-PTR with the ACE/MCU library is from $0.03 \% \Delta \mathrm{K} / \mathrm{K}$ to $-0.34 \% \Delta \mathrm{K} / \mathrm{K}$ for HEU and LEU fuel. It was concluded that for the conversion analysis of the IRT-type research reactor, it is better to use the MCU-PTR code with the ACE/MCU library from the perspective of better agreement with the MCNP results.

The SERPENT 2 and MCNP calculations generated the same value of $\mathrm{K}_{\mathrm{eff}}$ when the identical cross-section libraries are used.

A good agreement among the MCREB, MCU-PTR and SERPENT 2 results was observed for the test problem with burnup. The increase in the discrepancy among the codes in $\mathrm{K}_{\mathrm{eff}}$ after the first burnup cycle with LEU fuel was found to be less than $0.2 \% \Delta \mathrm{K} / \mathrm{K}$. That is, the relative error in the change in the excess reactivity $(\sim 11.5 \% \Delta \mathrm{K} / \mathrm{K})$ during the first burnup cycle was found to be $1.7 \%$.

It can be concluded that the developed models of the IRT-type reactor core are precise enough to reproduce the criticality, the excess reactivity and the reactivity change during the first burnup cycle with LEU fuel. Because the maximum burnup at the end of the cycle is approximately $30 \%$, further work is needed in the future to complete the validation investigations.

According to this study, there are differences between the considered codes and also between the cross-section libraries. The appropriate choice of the cross-section library for the particular problem enables a reduction of this difference. Achieving better agreement between the different codes used for the analysis of problems where experimental data are absent is a means to increase the reliability of the calculated predictions.

\section{Acknowledgments}

This work was supported by the U.S. Department of Energy, the National Nuclear Security Administration, and the Office of Defense Nuclear Nonproliferation, under contract DEAC02-06CH11357.

The work performed at NRNU MEPhI was also supported by the Ministry of Education and Science of the Russian Federation under Project 3092 in the framework of the basic part of the state task for scientific activities for educational organizations. 


\section{References}

[1] Peng Hong Liem, Tagor Malem Sembiring. Benchmarking the new JENDL-4.0 library on criticality experiments of a research reactor with oxide LEU (20 w/o) fuel, light water moderator and beryllium reflectors. Annals of Nuclear Energy 44 (2012), 58-64.

[2] P. Savva, M. Varvayanni, A.C. Fernandes, J.G. Marques, N. Catsaros. Comparing neutronics codes performance in analyzing a fresh-fuelled research reactor core. Annals of Nuclear Energy 63 (2014), 731-741.

[3] A.L. Izhutov, V.A. Starkov, V.V. Pimenov, V.E. Fedoseev et al. "The status of testing LEU U-Mo full-size IRT type fuel elements and mini-elements in the MIR reactor". In: Proceedings of the $30^{\text {th }}$ International Meeting on Reduced Enrichment for Research and Test Reactors RERTR 2008. Washington, D.C. USA, October 5-9, 2008. http://www.rertr.anl.gov/.

[4] X-5 Monte Carlo Team, MCNP - A General Monte Carlo N-Particle Transport Code, Version 5. LA-UR-03-1987 (2003).

[5] John G. Stevens, "The REBUS-MCNP Linkage", ANL/RERTR/TM-08-04, April 2008.

[6] Alekseev N.I., Gomin E.A., Marin S.V., Nasonov V.A., Shkarovskii D.A., Yudkevich M.S. MCU-PTR program for high-precision calculations of pool and tank type research reactors. Atomic Energy, 2011, Vol. 109, No. 3, pp. 149-156. DOI:10.1007/s10512011-9337-0

[7] Alekseev N.I., Bol'shagin S.N., Gomin E.A., Gorodkov S.S., Gurevich M.I., Kalugin M.A., Kulakov A.S., (...), Yudkevich M.S. The status of MCU-5. Physics of Atomic Nuclei, 2012, Vol. 75, No. 14, pp. 1634-1646. DOI:10.1134/S1063778812140025

[8] J. Leppänen. A new assembly-level Monte Carlo neutron transport code for reactor physics calculations. In M\&C 2005, Avignon, France, September 12-15, 2005.

[9] J. Leppänen. Use of the Serpent Monte Carlo reactor physics code for full-core calculations. In SNA+MC2010, Tokyo, Japan, October 17-21, 2010.

[10] N.A. Hanan, A.P. Olson, R.B. Pond, and J.E. Matos, "A Monte Carlo Burnup Code Linking MCNP and REBUS". In: Proceedings of the $20^{\text {th }}$ International Meeting on Reduced Enrichment for Research and Test Reactors RERTR 1998, São Paulo, Brazil, October 18-23, 1998. http://www.rertr.anl.gov/.

[11] A.P. Olson, "A Users Guide for the REBUS-PC Code, Version 1.4," ANL/RERTR/TM32 (Dec. 2001). 